\title{
Safety and efficacy of median sternotomy versus video- assisted thoracic surgery for lung volume reduction surgery
}

\author{
National Emphysema Treatment Trial Research Group*
}

Received for publication June 18, 2003; revisions requested Nov 5, 2003; revisions received Nov 10, 2003; accepted for publication Nov 20, 2003.

The writing committee of the National Emphysema Treatment Trial (Robert J. McKenna, Jr, MD, Cedars Sinai Medical Center, Los Angeles, Calif; Joshua O. Benditt, MD, University of Washington, Seattle, Wash; Malcolm DeCamp, MD, Cleveland Clinic Foundation, Cleveland, Ohio; Claude Deschamps, MD, Mayo Foundation, Rochester, Minn; Larry Kaiser, MD, University of Pennsylvania, Philadelphia, Pa; Shing M. Lee, ScM, Johns Hopkins University, Baltimore, Md; Zab Mohsenifar, MD, Cedars Sinai Medical Center, Los Angeles, Calif; Steven Piantadosi, MD, $\mathrm{PhD}$, Johns Hopkins University, Baltimore, Md; Scott Ramsey, MD, PhD, University of Washington, Seattle, Wash; John Reilly, MD, Brigham and Women's Hospital, Boston, Mass; and James Utz, MD, Mayo Foundation, Rochester, Minn) takes responsibility for the content of this article.

The National Emphysema Treatment Trial is supported by the National Heart, Lung, and Blood Institute (contracts N01HR76101, N01HR76102, N01HR76103, N01HR76104, N01HR76105, N01HR76106, N01HR76107, N01HR76108, N01HR76109, N01HR76110, N01HR76111, N01HR76112, N01HR76113, N01HR76114, N01HR76115, N01HR76116, N01HR76118, and N01HR76119), the Centers for Medicare and Medicaid Services, and the Agency for Healthcare Research and Quality.

Address for reprints: Steven Piantadosi, $\mathrm{MD}, \mathrm{PhD}$, NETT Coordinating Center, 615 N Wolfe St, Room 5010, Baltimore, MD 21205 .

*The members of the National Emphysema Treatment Trial Research Group are listed in Appendix 1.

J Thorac Cardiovasc Surg 2004;127: $1350-60$

$0022-5223 / \$ 30.00$

Copyright $(\odot) 2004$ by The American Association for Thoracic Surgery

doi:10.1016/j.jtcvs.2003.11.025
Background: The National Emphysema Treatment Trial, a randomized trial comparing lung volume reduction surgery with medical therapy for severe emphysema, included randomized and nonrandomized comparisons of the median sternotomy and video-assisted thoracoscopic approaches for lung volume reduction surgery.

Methods: Lung volume reduction surgery was performed by median sternotomy only at 8 centers and video-assisted thoracoscopy only at 3 centers; 6 centers randomized the approach to lung volume reduction surgery. Mortality, morbidity, functional status, and costs were assessed.

Results: In the nonrandomized comparison, 359 patients received lung volume reduction surgery by median sternotomy, and 152 patients received lung volume reduction surgery by video-assisted thoracoscopy. The 90-day mortality was $5.9 \%$ for median sternotomy and $4.6 \%$ for video-assisted thoracoscopy $(P=.67)$. Overall mortality was 0.08 deaths per person-year for median sternotomy and 0.10 deaths per person-year for video-assisted thoracoscopy (video-assisted thoracoscopy-median sternotomy risk ratio, $1.18 ; P=.42$ ). Complication rates were low and not statistically different for the 2 approaches. The median hospital length of stay was longer for median sternotomy than for video-assisted thoracoscopy (10 vs 9 days; $P$ $=.01$ ). By 30 days after surgery, $70.5 \%$ of median sternotomy patients and $80.9 \%$ of video-assisted thoracoscopy patients were living independently $(P=.02)$. Functional outcomes were similar for median sternotomy and video-assisted thoracoscopy at 12 and 24 months. Costs for the operation and the associated hospital stay and costs in the 6 months after surgery were both less for video-assisted thoracoscopy than for median sternotomy ( $P<.01$ in both cases). Similar results were noted for the randomized comparison.

Conclusions: Morbidity and mortality were comparable after lung volume reduction surgery by video-assisted thoracoscopy or median sternotomy, as were functional results. The video-assisted thoracoscopic approach to lung volume reduction surgery allowed earlier recovery at a lower cost than median sternotomy.

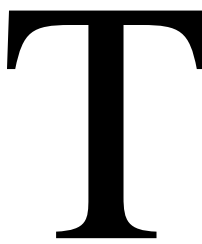

he optimal surgical approach for lung volume reduction surgery (LVRS) for advanced bilateral emphysema is unknown. Case series and early randomized trials have demonstrated the superiority of stapled over laser resection ${ }^{1}$ and of bilateral over unilateral operations. ${ }^{2}$ Case series support the use of either median sternotomy (MS) or video-assisted thoracoscopic (VATS) approaches. ${ }^{1-8}$ However, there are no data that directly compare the functional outcomes or longer-term results from these 2 approaches.

The National Emphysema Treatment Trial (NETT) was designed to compare the safety, efficacy, patient selection, and cost-effectiveness of LVRS with those of medical therapy for severe emphysema. ${ }^{9}$ Compared with medical management, LVRS produced a significant improvement in function for patients with upper lobe 
emphysema and improved survival for the subset of patients with upper lobe emphysema and a low baseline exercise capacity. ${ }^{10}$ A secondary goal of the NETT was to compare mortality, morbidity, and functional outcomes from the MS and VATS approaches to LVRS. These findings are reported in this article.

\section{Materials and Methods}

The design and methods of the NETT have been described previously $^{9}$ and are summarized below.

\section{Trial Protocol}

After completion of pulmonary rehabilitation, patients with bilateral severe emphysema judged suitable for LVRS were randomized in a 1:1 ratio to a program of continued medical therapy or medical therapy plus LVRS. Eight clinical centers performed LVRS by MS only and 3 by VATS only. Six centers performed both VATS and MS, and patients at those centers were randomized between the 2 approaches in a 1:1 ratio. Twenty-four surgeons provided LVRS in NETT. At sites that provided both approaches to LVRS, some surgeons performed both approaches. Some sites that provided only 1 type of LVRS had more than 1 NETT surgeon. Patients underwent bilateral stapled wedge resection through MS or VATS; the goal was to resect $20 \%$ to $35 \%$ of each lung, targeting the most diseased areas. Use of buttressing material was at the discretion of the surgeon. The trial protocol was approved by the institutional review board of each center, and all patients signed informed consent statements.

\section{Outcomes}

Outcomes included mortality, complications, hospital stay parameters (need for intensive care unit [ICU] care, need for mechanical ventilation, and length of stay), status at initial hospital discharge or 30 days after surgery, spirometry, exercise tolerance (assessed by cycle ergometry and distance walked in 6 minutes), quality of life, dyspnea, and costs. Respiratory disease-specific quality of life was assessed by the St George's Respiratory questionnaire, ${ }^{11}$ with scores ranging from 0 to 100 ; lower scores indicate less dyspnea. General quality of life was assessed by the Quality of Well-Being Scale, ${ }^{12}$ with scores ranging from 0 (death) to 1 (ideal). Changes in functional outcomes and quality of life were evaluated at 12 and 24 months after randomization.

\section{Statistical Analysis}

Two analyses of the MS versus VATS data are presented in this article. In the nonrandomized comparison, the pooled MS group (data from 14 centers) was compared with the pooled VATS group (data from 9 centers). In the randomized comparison, the MS and VATS groups at the 6 centers that randomized between MS and VATS were compared. In the tables that follow, data are presented for the nonrandomized comparison, and $P$ values are shown for both comparisons. Baseline characteristics were compared by using 2-sample $t$ tests for continuous variables and Fisher exact tests ${ }^{13}$ for categorical variables. The proportions of patients in each treatment group who died or had complications were compared by using Fisher exact or Freeman-Halton tests, ${ }^{14}$ depending on the number of categories. The risk ratio for death was estimated on the basis of the overall mortality in each group after a mean of 31.9 months of follow-up. ${ }^{15}$ Mortality was measured from the date of operation. Identification of subgroups of patients with differential mortality was performed with logistic regression analyses and a set of baseline prognostic factors, as described previously. ${ }^{10}$ Length of hospital stay was derived from Medicare claims data; the lengthof-stay data include stays that ended in death in the hospital, as well as discharge from the hospital. Changes from baseline in functional outcome were grouped into 10 to 12 categories ranked in order from greatest benefit to greatest deterioration, with death the worst outcome and missing data the next worst. The distributions of categories of change were compared by using the Wilcoxon rank sum test. ${ }^{13}$ Costs for the operation and associated hospital stay and the total costs (medical and nonmedical) for the 6 months from the date of operation were collected and valued as previously described. ${ }^{16}$ For the 6-month analysis, mean costs were estimated with the nonparametric Kaplan-Meier sample average estimator. ${ }^{17}$ This estimator sums monthly expected costs, where the expected costs for a month are the product of the Kaplan-Meier probability of surviving to the start of a month and the mean cost among survivors over that month. Mean costs for MS versus VATS derived from the Kaplan-Meier sample average estimator method were then compared by using 2-sample $t$ tests. Median costs for each group were also derived and compared by using the Wilcoxon rank sum test. All reported $P$ values are based on 2-sided tests.

\section{Results \\ Study Patients}

Between January 1998 and July 2002, 1218 patients were randomized in NETT (610 to medical treatment and 608 to LVRS). Interim analysis identified a subgroup of 140 patients (with a forced expiratory volume in 1 second $\leq 20 \%$ of predicted and either a homogeneous pattern of emphysema or a diffusing capacity of the lung for carbon monoxide of $\leq 20 \%$ predicted) at high risk for mortality after LVRS and with little chance of benefit from the operation. ${ }^{18}$ Patients who met these criteria were subsequently excluded from enrollment and were excluded from this analysis. Among the remaining 538 patients randomized to LVRS, 20 patients refused an operation and 7 patients were judged unsuitable for an operation after randomization, leaving 511 patients for analysis. The operation was performed via MS in 359 patients and via VATS in 152 patients. Baseline characteristics of these 511 patients are shown in Table 1. The MS and VATS groups were similar except for a larger proportion of patients with heterogeneous emphysema in the MS group compared with the VATS group (61\% vs $51 \%$, respectively; $P=.04$; Table 1 ). When the analysis was restricted to the centers that randomized patients to both approaches, the MS group (77 patients) and VATS group (71 patients) were comparable on all characteristics.

\section{LVRS Procedure}

Deviations from the surgical protocol (unilateral operation or bilateral operation performed in 2 sessions) occurred in 4 
TABLE 1. Characteristics of patients at baseline* $(n=511)$

\begin{tabular}{|c|c|c|}
\hline Characteristic & $\begin{array}{c}\text { Median } \\
\text { sternotomy } \\
(\mathrm{n}=359)\end{array}$ & $\begin{array}{c}\text { VATS } \\
(n=152)\end{array}$ \\
\hline Age at randomization (y) & $67.3 \pm 6.0$ & $66.3 \pm 6.7$ \\
\hline \multicolumn{3}{|l|}{ Sex, no $(\%)$} \\
\hline Female & $154(43)$ & $65(43)$ \\
\hline Male & $205(57)$ & $87(57)$ \\
\hline \multicolumn{3}{|l|}{$\begin{array}{l}\text { Emphysema distribution on CT, no } \\
(\%)\end{array}$} \\
\hline Predominantly upper lobe & $231(64)$ & $101(66)$ \\
\hline Predominantly non-upper lobe & $128(36)$ & $51(34)$ \\
\hline Heterogeneoust & $218(61)$ & $77(51)$ \\
\hline Homogeneoust & $141(39)$ & $75(49)$ \\
\hline Maximal workload (W) & $41.4 \pm 21.5$ & $38.2 \pm 21.2$ \\
\hline $\mathrm{FEV}_{1}$ after $\mathrm{BD}$ use ( $\%$ of predicted) & $27.9 \pm 6.6$ & $28.6 \pm 7.1$ \\
\hline TLC after BD use ( $\%$ of predicted) & $127.2 \pm 15.0$ & $127.6 \pm 15.3$ \\
\hline RV after BD use ( $\%$ of predicted) & $212.2 \pm 44.5$ & $219.6 \pm 47.7$ \\
\hline $\mathrm{D}_{\mathrm{L}} \mathrm{CO}(\%$ of predicted $)$ & $29.5 \pm 9.2$ & $28.4 \pm 9.6$ \\
\hline $\mathrm{PaO}_{2}(\mathrm{~mm} \mathrm{Hg})$ & $64.6 \pm 10.3$ & $66.6 \pm 11.2$ \\
\hline $\mathrm{PaCO}_{2}(\mathrm{~mm} \mathrm{Hg})$ & $42.8 \pm 5.5$ & $42.8 \pm 6.0$ \\
\hline St George's Respiratory total scoreł & $52.0 \pm 12.8$ & $53.1 \pm 12.6$ \\
\hline $\begin{array}{l}\text { UCSD Shortness of Breath total } \\
\text { score§ }\end{array}$ & $60.5 \pm 18.7$ & $60.9 \pm 17.6$ \\
\hline $\begin{array}{l}\text { Quality of Well-Being Scale average } \\
\text { daily score } \|\end{array}$ & $0.57 \pm 0.11$ & $0.59 \pm 0.12$ \\
\hline
\end{tabular}

$C T$, Computed tomography; $B D$, bronchodilator; $F E V_{1}$, forced expiratory volume in $1 \mathrm{~s} ; T L C$, total lung capacity; $R V$, residual volume; $D_{L} C O$, diffusing capacity of lung for carbon monoxide; $\mathrm{PaO}_{2}$, partial pressure of arterial oxygen; $\mathrm{PaCO}_{2}$, partial pressure of arterial carbon dioxide; VATS, videoassisted thoracoscopic surgery; UCSD, University of California-San Diego. *Baseline measurements were obtained after rehabilitation and before randomization except for $\mathrm{D}_{\mathrm{L}} \mathrm{cO}$, which was obtained before rehabilitation and before randomization. Plus-minus values are mean \pm SD.

tEmphysema distribution was based on scores assigned subjectively to each of 3 lung zones in each lung. $P$ value for homogeneity $=.04$.

†The St George Respiratory Questionnaire is a 51 -item questionnaire completed by the patient with regard to respiratory symptoms, in which the total score ranges from 0 to 100 and lower scores indicate fewer respiratory symptoms.

§The UCSD Shortness of Breath Questionnaire is a 24-item questionnaire completed by the patient with regard to shortness of breath, in which the total score ranges from 0 to 120 and lower scores indicate less shortness of breath.

\|The Quality of Well-Being Scale is a 77-item questionnaire completed by the patient with regard to quality of life. The average daily total score ranges from 0 to 1 , and higher scores indicate better quality of life.

MS patients and 8 VATS patients because of intraoperative factors. Table 2 compares features of the LVRS procedures performed with the MS and VATS approaches. The surgeons' estimates of the percentage of lung resected by MS were greater than their estimates of the percentage of lung resected by VATS; however, the grams of lung parenchyma resected by MS and VATS were not statistically different. When the analysis was restricted to the centers that randomized patients to MS and VATS, no differences were observed in the estimates of lung resected or in the grams of tissue resected.

\section{Mortality}

There were no intraoperative deaths in either treatment group. The 30-day mortality rate was $2.8 \%$ for MS and $2.0 \%$ for VATS $(P=.76)$, whereas the 90 -day mortality rate was $5.9 \%$ for MS and $4.6 \%$ for VATS $(P=.67)$. Similar results were observed when the analysis was restricted to the centers that randomized patients to both MS and VATS. During follow-up (mean, 31.9 months), 79 MS patients and 39 VATS patients died. The overall mortality rate was 0.08 deaths per person-year for MS patients and 0.10 deaths per person-year for VATS patients (risk ratio for death in the VATS group, 1.18; $P=.42$ ). No predictors of differential mortality by approach were identified.

\section{Intraoperative Experience}

There was no difference between the MS and VATS groups in mean blood loss (138.0 vs $127.4 \mathrm{~mL}$, respectively; $P=$ .55 ) or need for transfusion ( $3.1 \%$ vs $3.3 \% ; P=.99$ ), but the mean operating time was 21.7 minutes shorter for MS than for VATS (105.0 vs 126.7 minutes; $P<.001)$. When the analysis was restricted to the centers that randomized patients to MS and VATS, the mean operating time was 8.8 minutes shorter for MS than for VATS, but the difference was not statistically significant $(P=.30)$.

A total of $93.0 \%$ of the MS patients and $86.2 \%$ of the VATS patients had no intraoperative complications $(P=$ .02 ; Table 3 ). Hypoxemia was the only intraoperative complication that occurred with a different frequency with MS versus VATS (0.8\% vs $5.3 \%$, respectively; $P=.004)$. When the analysis was restricted to the centers that randomized to MS and VATS, there were no differences in the percentage of patients without complications or in the rates of specific complications.

\section{Experience During the 30 Days After LVRS}

The only statistically different postoperative complication was the need to reoperate for air leak (MS, 2.2\%; VATS, $5.9 \% ; P=.05$; Table 3 ), but when the analysis was restricted to centers that randomized patients to both MS and VATS, there was no difference in the frequency of need to reoperate for air leak. However, in the randomized comparison, failure to wean differed between groups $(7.8 \%$, MS; $0 \%$, VATS; $P=.03$ ).

Table 4 shows the assessment of air leak at the completion of LVRS, the number of days with air leak for patients who survived at least 30 days, and the percentage of patients who died within 30 days of LVRS. Although there was a higher incidence of air leak at the end of the VATS procedure than at the end of the MS procedure $(P=.01)$, there was no difference between groups in the number of days with air leak $(P=.74)$. Air leak on 7 or more days occurred in $46 \%$ of MS patients, versus $49 \%$ of VATS patients $(P=$ 
TABLE 2. Features of the LVRS procedure* $(n=511)$

\begin{tabular}{|c|c|c|c|c|}
\hline \multirow[b]{2}{*}{ Variable } & \multicolumn{3}{|c|}{ Nonrandomized comparison } & \multirow[b]{2}{*}{$P$ valuef } \\
\hline & $\begin{array}{l}\text { Median sternotomy } \\
\qquad(\mathrm{n}=359)\end{array}$ & $\begin{array}{c}\text { VATS } \\
\text { (n = 152) }\end{array}$ & $P$ valuet & \\
\hline \multicolumn{5}{|c|}{ Surgeon's estimate of amount of right lung removed $(\%)$} \\
\hline$<20$ & $0.6 \%$ & $0.0 \%$ & & \\
\hline $20-34$ & $61.8 \%$ & $78.0 \%$ & & \\
\hline $35-49$ & $32.0 \%$ & $18.7 \%$ & & \\
\hline$\geq 50$ & $5.6 \%$ & $3.3 \%$ & .003 & .25 \\
\hline \multicolumn{5}{|c|}{ Surgeon's estimate of amount of left lung removed $(\%)$} \\
\hline$<20$ & $0.6 \%$ & $0.0 \%$ & & \\
\hline $20-34$ & $65.0 \%$ & $85.3 \%$ & & \\
\hline $35-49$ & $26.3 \%$ & $10.7 \%$ & & \\
\hline$\geq 50$ & $8.2 \%$ & $4.0 \%$ & $<.001$ & .08 \\
\hline Weight of right lung resected $(\mathrm{g})$ & $68.0 \pm 30.8$ & $62.8 \pm 51.8$ & .17 & .18 \\
\hline Weight of left lung resected $(\mathrm{g})$ & $70.4 \pm 51.8$ & $61.7 \pm 73.3$ & .14 & .35 \\
\hline \multicolumn{5}{|c|}{$\begin{array}{l}\text { LVRS, Lung volume reduction surgery; VATS, video-assisted thoracoscopic surgery; } F E V_{1} \text {, forced expiratory volume in } 1 \mathrm{~s} ; C T \text {, computed tomography; } D_{L} C O \text {, } \\
\text { diffusing capacity of lung for carbon monoxide; NETT, National Emphysema Treatment Trial. } \\
\text { *Patients with } F E V_{1} \leq 20 \% \text { predicted and either homogeneous emphysema on CT scan or } D_{L} C 0 \geq 20 \% \text { predicted were excluded, as were patients assigned } \\
\text { to LVRS who did not receive LVRS within NETT. } \\
\text { † } P \text { values for differences in means ( } t \text { test) or homogeneity (Freeman-Halton test). } \\
\ddagger \text { Randomized comparison of median sternatomy ( } \mathrm{n}=77 \text { ) with VATS ( } \mathrm{n}=71): P \text { values for differences in means ( } t \text { test) or homogeneity (Freeman-Halton } \\
\text { test). }\end{array}$} \\
\hline
\end{tabular}

.48). When the analysis was restricted to centers that randomized patients to both MS and VATS, there was no difference between groups in the presence of air leak at closure or in the number of days with air leak.

Table 5 shows the number of days in the ICU, the number of days on ventilator support for patients who survived at least 30 days after LVRS, and the percentage of patients who died within 30 days of LVRS. Days in the ICU differed by approach $(P<.001)$; patients in the MS group required more ICU days after surgery than patients in the VATS group. The difference in distributions was not statistically significant when the analysis was restricted to the centers that randomized patients to both MS and VATS. Need for mechanical ventilation in the 30 days after LVRS was similar for both groups; more than $80 \%$ of patients in each treatment group required mechanical ventilation for 1 day or less.

Hospital length of stay was available from Medicare claims for 343 MS patients and 146 VATS patients (489 patients total; 6 patients were enrolled in a Medicare + Choice plan or insured by non-Medicare insurers, and claims for the LVRS procedure could not be located for an additional 16 individuals). Length of hospital stay was analyzed whether the stay ended in hospital discharge or death. The length of hospital stay (mean \pm SD) was 17 \pm 19 days for MS patients versus $14 \pm 9$ days for VATS patients $(P=.06)$. The median length of stay was 10 days for MS patients and 9 days for VATS patients $(P=.01)$. When the comparison was restricted to the centers that randomized patients to both MS (75 patients) and VATS (67 patients), the length of hospital stay was $19 \pm 15$ days for MS patients versus $13 \pm 15$ days for VATS patients $(P=$ $.02)$, and the median length of stay was 15 days for MS patients and 9 days for VATS patients $(P<.001)$.

\section{Residence}

By 30 days after surgery, $70.5 \%$ of MS patients and $80.9 \%$ of VATS patients were living independently $(P=.02)$. When the comparison was restricted to the centers that randomized patients to MS and VATS, the difference in the percentage of patients who were living independently was greater $(62.3 \%$, MS; $87.3 \%$, VATS; $P=.001)$. By 4 months after randomization, the percentages were $87.5 \%$ and $90.8 \%$ $(P=.36)$, respectively, for the nonrandomized comparison and $83.1 \%$ and $90.1 \%(P=.24)$, respectively, for the randomized comparison.

\section{Functional Outcomes}

Histograms of the changes from postrehabilitation baseline in exercise capacity, forced expiratory volume in 1 second percentage of predicted, 6-minute walk distance, St George's Respiratory questionnaire, and Quality of WellBeing Scale after 12 and 24 months of follow-up (measured since randomization) are shown in Figure 1. Outcomes for individual patients varied widely regardless of approach, but the distributions of change were similar for both approaches. Similar results were observed when the analysis 
TABLE 3. Complications* $(n=511)$

\begin{tabular}{|c|c|c|c|c|}
\hline \multirow[b]{2}{*}{ Complication } & \multicolumn{3}{|c|}{ Nonrandomized comparison } & \multirow[b]{2}{*}{$P$ valuef } \\
\hline & $\begin{array}{l}\text { Median sternotomy } \\
\qquad(\mathrm{n}=359)\end{array}$ & $\begin{array}{c}\text { VATS } \\
(n=152)\end{array}$ & $P$ valuet & \\
\hline \multicolumn{5}{|l|}{ Intraoperative } \\
\hline None & $93.0 \%$ & $86.2 \%$ & .02 & .80 \\
\hline Hypotension & $0.3 \%$ & $0.7 \%$ & .51 & .99 \\
\hline Arrhythmia & $1.7 \%$ & $0 \%$ & .19 & .99 \\
\hline Hypoxemia & $0.8 \%$ & $5.3 \%$ & .004 & .25 \\
\hline Hypercarbia & $0.8 \%$ & $2.6 \%$ & .20 & .99 \\
\hline Cardiac arrest & $0.3 \%$ & $0.7 \%$ & .51 & $-\S$ \\
\hline Uncontrolled air leak & $0.8 \%$ & $1.3 \%$ & .64 & .62 \\
\hline Other & $3.3 \%$ & $4.6 \%$ & .46 & .26 \\
\hline \multicolumn{5}{|l|}{ Postoperative } \\
\hline None & $41.6 \%$ & $48.0 \%$ & .20 & .10 \\
\hline Atrial fibrillation & $2.5 \%$ & $1.3 \%$ & .52 & .68 \\
\hline Arrhythmia & $21.3 \%$ & $21.2 \%$ & .99 & .40 \\
\hline Failure of early extubation & $3.1 \%$ & $6.0 \%$ & .14 & .67 \\
\hline Tracheostomy & $9.2 \%$ & $5.9 \%$ & .29 & .21 \\
\hline Failure to wean & $6.1 \%$ & $2.6 \%$ & .12 & .03 \\
\hline Reoperation for air leak & $2.2 \%$ & $5.9 \%$ & .05 & .99 \\
\hline Pulmonary embolus & $0.6 \%$ & $1.3 \%$ & .59 & .48 \\
\hline Readmission to ICU & $11.4 \%$ & $12.5 \%$ & .76 & .60 \\
\hline Mediastinitis & $0.8 \%$ & $0 \%$ & .56 & $-\S$ \\
\hline Sternal debridement & $0.8 \%$ & $0 \%$ & .56 & $-\S$ \\
\hline Pneumonia & $20.1 \%$ & $13.8 \%$ & .10 & .15 \\
\hline Urinary retention & $4.2 \%$ & $2.0 \%$ & .30 & .68 \\
\hline Epidural catheter complications & $1.1 \%$ & $0 \%$ & .32 & .99 \\
\hline Sepsis & $2.0 \%$ & $4.0 \%$ & .22 & .35 \\
\hline Readmission within $72 \mathrm{~h}$ after discharge & $2.2 \%$ & $3.3 \%$ & .54 & .35 \\
\hline
\end{tabular}

VATS, Video-assisted thoracoscopic surgery; ICU, intensive care unit; $F E V_{1}$, forced expiratory volume in $1 \mathrm{~s} ; C T$, computed tomography; $D_{L} C O$, diffusing capacity of lung for carbon monoxide; LVRS, lung volume reduction surgery; NETT, National Emphysema Treatment Trial.

${ }^{*}$ Patients with $\mathrm{FEV}_{1} \leqslant 20 \%$ predicted and either homogeneous emphysema on CT scan or $D_{L} \mathrm{CO} \leqslant 20 \%$ predicted were excluded, as were patients assigned to LVRS who did not receive LVRS within NETT. More than 1 complication could be reported for a patient.

t $P$ values for homogeneity (Fisher exact test).

‡Randomized comparison of median sternotomy $(n=77)$ with VATS $(n=71)$ : $P$ values for homogeneity (Fisher exact test).

$\S$ The specified complication did not occur in either treatment group under the randomized comparison.

was restricted to centers that randomized patients to both MS and VATS.

\section{Costs}

Costs were analyzed for the 489 patients for whom Medicare claims data were available (343 MS patients and 146 VATS patients) and are shown in Table 6. Mean hospital and physician costs for the LVRS admission were $\$ 8207$ less for the VATS group compared with the MS group (95\% confidence interval $[\mathrm{CI}]$ on difference, $\$ 917-\$ 16,035 ; P=$ .03 ). Mean total costs (medical and nonmedical) during the 6 months after surgery were $\$ 10,428$ lower for the VATS group (95\% CI on difference, $\$ 9786-\$ 109,062 ; P=.005$ ). When the comparison was restricted to the centers that randomized patients to MS and VATS (75 MS patients and 67 VATS patients), mean hospital and physician costs for the LVRS admission were $\$ 7138$ less for the VATS group compared with the MS group (95\% CI on difference, \$5900-
$\$ 20,177 ; P=.28)$. Mean total costs during the 6 months after surgery were $\$ 6500$ lower for the VATS group (95\% CI on difference, $\$ 4295-\$ 8,705 ; P<.001)$.

\section{Differences Between Centers}

All centers had similar percentages of patients dead by 30 days after surgery $(P=.37)$ and similar percentages of patients without postoperative complications $(P=.51)$.

\section{Discussion}

This is the largest direct comparison of LVRS by MS and VATS approaches, and it included a subset of patients for whom the surgical approach was randomly assigned. We found that the 2 approaches carry similar risks of 30-day, 90-day, and overall mortality; have similar complication rates; and have similar changes in exercise capacity, lung function, and general and disease-specific quality of life. 
TABLE 4. Air leak at closure and in the 30 days after surgery* $(n=511)$

\begin{tabular}{|c|c|c|c|c|}
\hline \multirow[b]{2}{*}{ Variable } & \multicolumn{3}{|c|}{ Nonrandomized comparison } & \multirow[b]{2}{*}{$P$ valuef } \\
\hline & Median sternotomy & VATS & $P$ valuet & \\
\hline \multicolumn{5}{|l|}{ Air leak at closure } \\
\hline None & $45.7 \%$ & $34.2 \%$ & & \\
\hline Occasional bubble or pinhole stream & $37.3 \%$ & $37.5 \%$ & & \\
\hline Intermediate stream of bubbles with respiratory variation & $14.2 \%$ & $25.0 \%$ & & \\
\hline Large stream of nearly constant bubbles & $2.8 \%$ & $3.3 \%$ & .01 & .08 \\
\hline No. of patients & 359 & 152 & & \\
\hline \multicolumn{5}{|l|}{ Days with air leak in the $30 \mathrm{~d}$ after surgery } \\
\hline \multicolumn{5}{|l|}{ Alive $30 \mathrm{~d}$ after surgery } \\
\hline $0 \mathrm{~d}$ with air leak & $10.9 \%$ & $11.0 \%$ & & \\
\hline 1-6 d with air leak & $40.1 \%$ & $37.9 \%$ & & \\
\hline 7-14 d with air leak & $21.5 \%$ & $22.1 \%$ & & \\
\hline $15-29 \mathrm{~d}$ with air leak & $14.8 \%$ & $12.4 \%$ & & \\
\hline$\geq 30 \mathrm{~d}$ with air leak & $9.7 \%$ & $14.5 \%$ & & \\
\hline Dead within $30 \mathrm{~d}$ of surgery & $3.0 \%$ & $2.1 \%$ & .74 & .39 \\
\hline No. of patients & $339 \S$ & $145 \S$ & & \\
\hline
\end{tabular}

VATS, Video-assisted thoracoscopic surgery; $F E V_{1}$, forced expiratory volume in $1 \mathrm{~s} ; C T$, computed tomography; $D_{L} C O$, diffusing capacity of lung for carbon monoxide; LVRS, lung volume reduction surgery; NETT, National Emphysema Treatment Trial.

*Patients with $\mathrm{FEV}_{1} \leqslant 20 \%$ predicted and either homogeneous emphysema on CT scan or $\mathrm{D}_{\mathrm{L}} \mathrm{CO} \leqslant 20 \%$ predicted were excluded, as were patients assigned to LVRS who did not receive LVRS within NETT.

† $P$ values for homogeneity (Freeman-Halton test).

‡Randomized comparison of median sternotomy $(n=77)$ with VATS $(n=71)$ : $P$ values for homogeneity (Freeman-Halton test).

$\S$ Data on air leak after closure were missing for 20 median sternotomy patients and 7 VATS patients who survived $30 \mathrm{~d}$ after surgery.

TABLE 5. Days in ICU and days on mechanical ventilation* $(n=511)$

\begin{tabular}{|c|c|c|c|c|}
\hline \multirow[b]{2}{*}{ Variable } & \multicolumn{3}{|c|}{ Nonrandomized comparison } & \multirow[b]{2}{*}{$P$ value } \\
\hline & Median sternotomy & VATS & $P$ valuet & \\
\hline \multicolumn{5}{|l|}{ Days in ICU } \\
\hline \multicolumn{5}{|l|}{ Alive $30 \mathrm{~d}$ after LVRS } \\
\hline $0-1 \mathrm{~d}$ in ICU & $43.1 \%$ & $65.1 \%$ & & \\
\hline $2 \mathrm{~d}$ in ICU & $15.3 \%$ & $6.6 \%$ & & \\
\hline $3-29 \mathrm{~d}$ in ICU & $36.2 \%$ & $24.3 \%$ & & \\
\hline$\geq 30 \mathrm{~d}$ in ICU & $2.3 \%$ & $2.0 \%$ & & \\
\hline Dead within $30 \mathrm{~d}$ of LVRS & $2.8 \%$ & $2.0 \%$ & $<.001$ & .76 \\
\hline No. of patients & 354 & 152 & & \\
\hline \multicolumn{5}{|l|}{ Days on mechanical ventilation } \\
\hline \multicolumn{5}{|l|}{ Alive $30 \mathrm{~d}$ after LVRS } \\
\hline $0 \mathrm{~d}$ on ventilator & $76.2 \%$ & $75.7 \%$ & & \\
\hline $1 \mathrm{~d}$ on ventilator & $6.4 \%$ & $8.6 \%$ & & \\
\hline 2-14 d on ventilator & $6.2 \%$ & $7.2 \%$ & & \\
\hline $15-29 \mathrm{~d}$ on ventilator & $7.6 \%$ & $6.6 \%$ & & \\
\hline$\geq 30 \mathrm{~d}$ on ventilator & $0.8 \%$ & $0 \%$ & .86 & .64 \\
\hline Dead within $30 \mathrm{~d}$ of LVRS & $2.8 \%$ & $2.0 \%$ & & \\
\hline No. of patients & 357 & 152 & & \\
\hline
\end{tabular}

ICU, Intensive care unit; VATS, video-assisted thoracoscopic surgery; LVRS, lung volume reduction surgery; $F E V_{1}$, forced expiratory volume in 1 s; $C T$, computed tomography; $D_{L} C O$, diffusing capacity of lung for carbon monoxide; NETT, National Emphysema Treatment Trial.

*Patients with $\mathrm{FEV}_{1} \leqslant 20 \%$ predicted and either homogeneous emphysema on CT scan or $\mathrm{D}_{\mathrm{L}} \mathrm{C} 0 \leqslant 20 \%$ predicted were excluded, as were patients assigned to LVRS who did not receive LVRS within NETT.

$\dagger P$ values for homogeneity (Freeman-Halton test).

‡Randomized comparison of median sternotomy $(\mathrm{n}=77)$ to VATS $(\mathrm{n}=71)$ : $P$ values for homogeneity (Freeman-Halton test).

The MS approach incurred slightly longer ICU and hospital lengths of stay and greater costs.

Because LVRS is a palliative, elective procedure, one of the greatest concerns was the mortality rate for the proce- dure. Reported operative mortality rates were generally $3.5 \%$ to $10 \%$, but some were as high as $19.1 \% .^{4-8,19,20}$ Moreover, on the basis of data for Medicare patients who underwent LVRS between October 1995 and January 1996, 

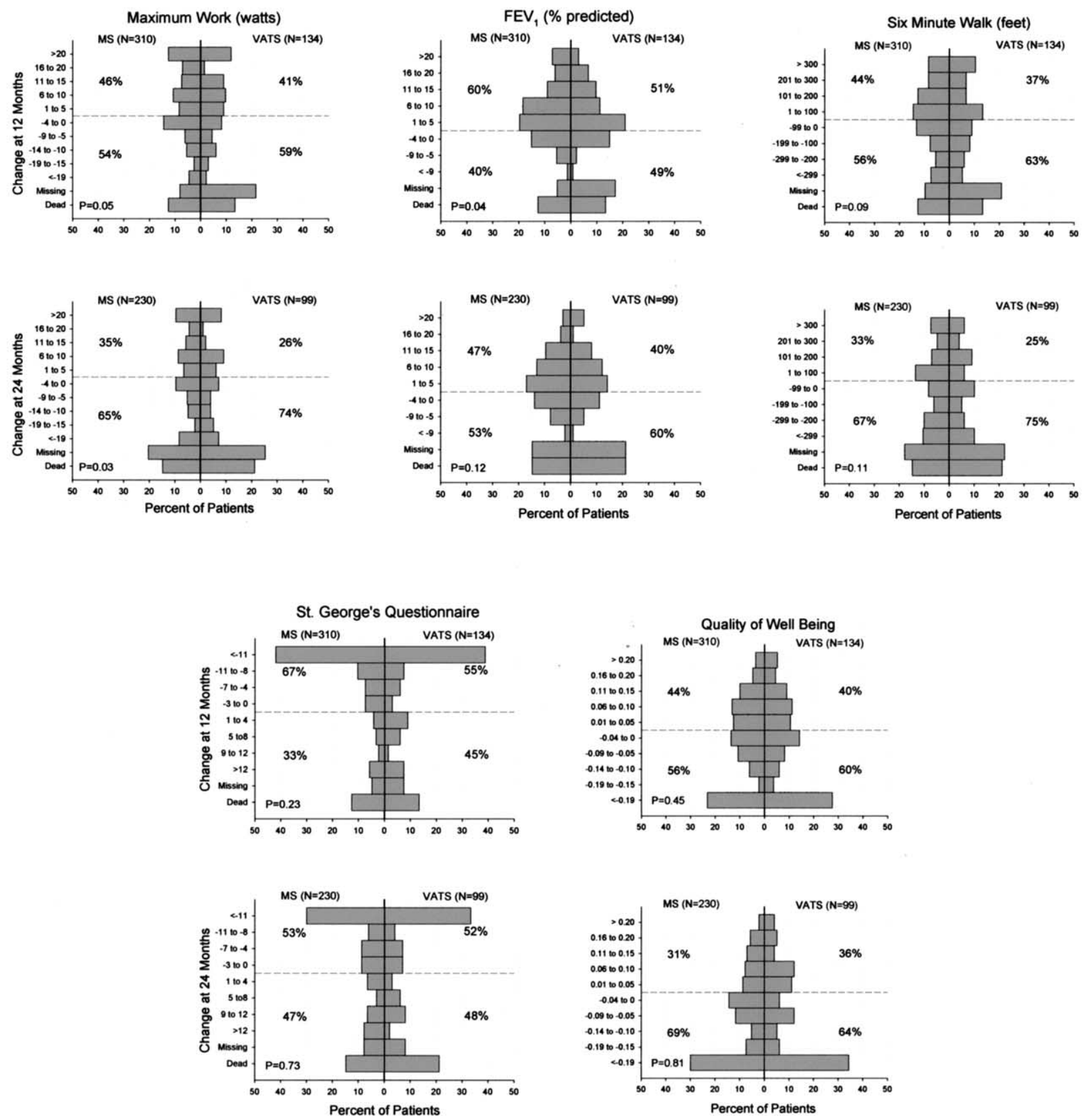

Figure 1. Histograms of changes from postrehabilitation baseline in exercise capacity (maximum work), forced expiratory volume in 1 second $\left(F E V_{1}\right)$ percentage predicted, 6-minute walk distance, St George's Respiratory Questionnaire, and Quality of Well-Being Scale after 12 and 24 months of follow-up (measured from randomization). The category "Missing" includes patients too ill to complete the procedure and patients who refused to complete the procedure but did not provide information about why they did not complete the procedure. For the Quality of Well-Being Scale, patients who died were given a value of 0 on the questionnaire for the visit, and patients who did not complete the questionnaire were assigned a value equal to one half the lowest score observed for the visit. The $\boldsymbol{P}$ values for disparity in outcome distributions between the median sternotomy (MS) and video-assisted thoracoscopy (VATS) groups were determined from Wilcoxon rank sum tests; the degree to which the bars are shifted to the upper left of the chart indicates the degree of relative benefit of MS over VATS. The percentage shown in each quadrant is the percentage of patients in the specified treatment group with change in the outcome in that quadrant. Patients with $\mathrm{FEV}_{1}$ less than or equal to $20 \%$ predicted and either homogeneous emphysema or diffusing capacity of the lung for carbon monoxide less than or equal to $20 \%$ of predicted were excluded, as were patients assigned to LVRS who did not receive LVRS within NETT. 
TABLE 6. Costs* $(n=489)$

\begin{tabular}{|c|c|c|c|c|}
\hline \multirow[b]{2}{*}{ Variable } & \multicolumn{3}{|c|}{ Nonrandomized comparison } & \multirow[b]{2}{*}{$P$ value‡ } \\
\hline & $\begin{array}{l}\text { Median sternotomy } \\
\qquad(\mathrm{n}=343)\end{array}$ & $\begin{array}{c}\text { VATS } \\
(n=146)\end{array}$ & $P$ valuet & \\
\hline \multicolumn{5}{|l|}{ Cost for LVRS and associated hospital stay§ } \\
\hline $\begin{array}{l}\text { Mean } \pm \text { SD } \\
\text { Median }\end{array}$ & $\begin{array}{l}\$ 38,557 \pm \$ 40,519 \\
\$ 23,418\end{array}$ & $\begin{array}{c}\$ 30,350 \pm \$ 37,219 \\
\$ 19,947\end{array}$ & .03 & .28 \\
\hline Total costs for 6 mo after LVRS (mean \pm SD)\| & $\$ 61,481 \pm \$ 3189$ & $\$ 51,053 \pm \$ 4502$ & .005 & $<.001$ \\
\hline \multicolumn{5}{|c|}{$\begin{array}{l}\text { VATS, Video-assisted thoracoscopic surgery; } F E V_{1} \text {, forced expiratory volume in } 1 \mathrm{~s} ; C T \text {, computed tomography; } D_{L} C O \text {, diffusing capacity of lung for carbon } \\
\text { monoxide; } L V R S \text {, lung volume reduction surgery; NETT, National Emphysema Treatment Trial. } \\
\text { *Patients with } F E V_{1} \leqslant 20 \% \text { predicted and either homogeneous emphysema on } C T \text { scan or } D_{L} C 0 \leqslant 20 \% \text { predicted were excluded, as were patients assigned } \\
\text { to LVRS who did not receive LVRS within NETT and } 22 \text { patients for whom Medicare claims were not available. } \\
t P \text { values for differences in means ( } t \text { test). }\end{array}$} \\
\hline
\end{tabular}

a mortality rate of $14.4 \%$ was found at 3 months and $23 \%$ at 12 months. ${ }^{21}$ However, in this prospective multicenter study, the NETT observed a 90-day mortality for LVRS of $5.9 \%$ for MS and $4.6 \%$ for VATS.

Postoperative morbidity after LVRS has been a source of concern. The morbidity for the MS and VATS approaches to LVRS showed very little difference. Although there was a slight trend for higher 30-day mortality after MS than after VATS, this was not statistically significant. The median hospital length of stay was longer for MS than for VATS. The rate of complications was low for both approaches and was not statistically different.

Air leak lasting 7 or more days is the most commonly reported complication after LVRS and occurs in approximately half of patients. ${ }^{4-8,19,20}$ The NETT data for air leak are similar to published data. The VATS patients had a higher incidence of air leak at closure than the MS patients; this is presumably because intraoperative identification and elimination of air leaks is more difficult for a VATS approach than for an MS approach. However, there was no difference between the MS and VATS groups in the percentage of patients with air leak for 7 or more days.

The analysis of functional outcomes demonstrated only slight differences between MS and VATS. The VATS patients achieved independent living after LVRS slightly earlier than the MS patients $(P=.001)$. However, at 12 and 24 months after randomization, the functional outcomes were essentially identical for MS and VATS.

The cost analysis demonstrated that patients who underwent VATS had significantly lower costs for the initial hospital stay. The lower costs likely reflect fewer ICU days and a reduced overall length of stay for the VATS group. Overall costs at 6 months were also lower for the VATS group.

The results of this study must be interpreted in light of the use of randomization for only a portion (29\%) of the sample. Randomization was used at centers that were capable of offering and willing to offer both procedures. Some surgeons felt comfortable with either procedure, whereas at other centers, all of the procedures of a given type were performed by an individual surgeon. In any case, we think that it is important to present all of the NETT data that bear on the question of MS versus VATS. The results demonstrate the importance of randomization-a number of seemingly significant differences in the nonrandomized comparisons disappeared in the randomized subset. This is not due to the smaller sample size in the randomized comparison, because the effect size diminished or disappeared in these circumstances.

In conclusion, the data from the NETT show that complication rates do not significantly differ for the 2 procedures. Although the recovery seems to be earlier and the costs less for the VATS approach, there is no difference between the MS and VATS patients with respect to the functional results at 12 and 24 months after randomization. Patients with prior sternotomy or unilateral emphysema were excluded from the NETT. In such patients, VATS may be preferable. However, for patients without prior chest operation and with bilateral emphysema, either approach confers the same low risk of operative mortality and the same opportunity for benefits. The choice of approach is a matter of the surgeon's preference and experience.

We thank Arthur Gelb, MD, Lakewood Regional Medical Center, Lakewood, Calif.

\section{References}

1. McKenna RJ Jr, Brenner M, Gelb AF, Mullin M, Singh N, Peters H, et al. A randomized prospective trial of stapled lung reduction versus laser bullectomy for diffuse emphysema. J Thorac Cardiovasc Surg. 1996;111:317-22.

2. McKenna RJ Jr, Brenner M, Fischel RJ, Gelb AF. Should lung reduction surgery for emphysema be unilateral or bilateral? $J$ Thorac Cardiovasc Surg. 1996;112:1331-9. 
3. Cooper JD, Trulock EP, Triantafillou AN, Patterson GA, Pohl MS, Deloney PA, et al. Bilateral pneumectomy (volume reduction) for chronic obstructive pulmonary disease. J Thorac Cardiovasc Surg. 1995;109:106-16.

4. Miller JI, Lee RB, Mansour KA. Lung volume reduction surgery: lessons learned. Ann Thorac Surg. 1996;61:1464-9.

5. Miller DL, Dowling RD, McConnell JW, Skolnick JL. Effects of lung volume reduction surgery on lung and chest wall mechanics. Presented at the annual meeting of The Society of Thoracic Surgeons, 1996.

6. Argenziano M, Moazami N, Thomashaw B, et al. Extended indications for lung volume reduction surgery in advanced emphysema. Ann Thorac Surg. 1996;62:1588-97.

7. Wisser W, Tschernko E, Senbaklavaci O, et al. Functional improvement after volume reduction: sternotomy versus videoendoscopic approach. Ann Thorac Surg. 1997;63:822-7.

8. Kotloff RM, Tino G, Bavaria JE, et al. Bilateral lung volume reduction surgery for advanced emphysema. Chest. 1996;110:1399-406.

9. National Emphysema Treatment Trial Research Group. Rationale and design of the National Emphysema Treatment Trial (NETT): a prospective randomized trial of lung volume reduction surgery. J Thorac Cardiovasc Surg. 1999;188:518-28.

10. National Emphysema Treatment Trial Research Group. A randomized trial comparing lung volume reduction surgery with medical therapy for severe emphysema. N Engl J Med. 2003;348:2059-73.

11. Jones PW, Quirk FH, Baveystock CM, Littlehohns P. A self-complete measure of health status for chronic airflow limitation: the St. George's Respiratory Questionnaire. Am Rev Respir Dis. 1992;145:1321-7.

12. Kaplan RM, Anderson JP. The general health policy model: an integrated approach. In: Spilker B, editor. Quality of life and pharmacoeconomics in clinical trials. 2nd ed. Philadelphia: Lippincott-Raven; 1996. p. 309-22.

13. Agresti A. An introduction to categorical data analysis. New York: John Wiley \& Sons; 1996.

14. Freeman GH, Halton JH. Note on an exact treatment of contingency goodness of fit and other problems of significance. Biometrika. 1951; 38:141-9.

15. Stata reference manual, version 7. College Station (TX): Stata Press; 2001.

16. National Emphysema Treatment Trial Research Group. Cost effectiveness of lung volume reduction surgery for patients with severe emphysema. N Engl J Med. 2003;348:2092-102.

17. Lin DY, Feuer EJ, Etzioni R, Wax Y. Estimating medical costs from incomplete follow-up data. Biometrics. 1997;53:419-34.

18. The National Emphysema Treatment Trial Research Group. Patients at high risk of mortality after lung volume reduction surgery. New Engl J Med. 2001;345:1075-83.

19. Bingisser R, Zollinger A, Hauser M, Bloch KE, Russi EW, Weder W. Bilateral volume reduction surgery for diffuse pulmonary emphysema by video-assisted thoracoscopy. J Thorac Cardiovasc Surg. 1996;112: 875-82.

20. Cooper JD, Patterson GA, Sundaresan RS, et al. Results of 150 consecutive bilateral lung volume reduction procedures in patients with severe emphysema. J Thorac Cardiovasc Surg. 1996;112:131930 .

21. Health Care Financing Administration. Report to Congress: lung volume reduction surgery and Medicare coverage policy-implications of recently published evidence. Donna E. Shalala, Health and Human Services. 1998.

\section{Appendix 1: Members of the NETT Research Group} Office of the Chair of the Steering Committee, University of Pennsylvania, Philadelphia, Pa: Alfred P. Fishman, MD (chair); Betsy Ann Bozzarello; Ameena Al-Amin.

\section{Clinical Centers}

Baylor College of Medicine, Houston, Tex: Marcia Katz, MD (principal investigator); Carolyn Wheeler, RN, BSN (principal clinical coordinator); Elaine Baker, RRT, RPFT; Peter Barnard, PhD, RPFT; Phil Cagle, MD; James Carter, MD; Sophia Chatzi- ioannou, MD; Karla Conejo-Gonzales; Kimberly Dubose, RRT; John Haddad, MD; David Hicks, RRT, RPFT; Neal Kleiman, MD; Mary Milburn-Barnes, CRTT; Chinh Nguyen, RPFT; Michael Reardon, MD; Joseph Reeves-Viets, MD; Steven Sax, MD; Amir Sharafkhaneh, MD; Owen Wilson, PhD; Christine Young, PT; Rafael Espada, MD (principal investigator, 1996-2002); Rose Butanda (1999-2001); Minnie Ellisor (2002); Pamela Fox, MD (1999-2001); Katherine Hale, MD (1998-2000); Everett Hood, RPFT (1998-2000); Amy Jahn (1998-2000); Satish Jhingran, MD (1998-2001); Karen King, RPFT (1998-1999); Charles Miller III, $\mathrm{PhD}$ (1996-1999); Imran Nizami, MD (co-principal investigator, 2000-2001); Todd Officer (1998-2000); Jeannie Ricketts (19982000); Joe Rodarte, MD (co-principal investigator, 1996-2000); Robert Teague, MD (co-principal investigator, 1999-2000); and Kedren Williams (1998-1999).

Brigham and Women's Hospital, Boston, Mass: John Reilly, MD (principal investigator); David Sugarbaker, MD (co-principal investigator); Carol Fanning, RRT (principal clinic coordinator); Simon Body, MD; Sabine Duffy, MD; Vladmir Formanek, MD; Anne Fuhlbrigge, MD; Philip Hartigan, MD; Sarah Hooper, EP; Andetta Hunsaker, MD; Francine Jacobson, MD; Marilyn Moy, MD; Susan Peterson, RRT; Roger Russell, MD; Diane Saunders; and Scott Swanson, MD (co-principal investigator, 1996-2001).

Cedars-Sinai Medical Center, Los Angeles, Calif: Rob McKenna, MD (principal investigator); Zab Mohsenifar, MD (coprincipal investigator); Carol Geaga, RN (principal clinic coordinator); Manmohan Biring, MD; Susan Clark, RN, MN; Jennifer Cutler, MD; Robert Frantz, MD; Peter Julien, MD; Michael Lewis, MD; Jennifer Minkoff-Rau, MSW; Valentina Yegyan, BS, CPFT; and Milton Joyner, BA (1996-2002).

Cleveland Clinic Foundation, Cleveland, Ohio: Malcolm DeCamp, MD (principal investigator); James Stoller, MD (coprincipal investigator); Yvonne Meli, RN, C (principal clinic coordinator); John Apostolakis, MD; Darryl Atwell, MD; Jeffrey Chapman, MD; Pierre DeVilliers, MD; Raed Dweik, MD; Erik Kraenzler, MD; Rosemary Lann, LISW; Nancy Kurokawa, RRT, CPFT; Scott Marlow, RRT; Kevin McCarthy, RCPT; Pricilla McCreight, RRT, CPFT; Atul Mehta, MD; Moulay Meziane, MD; Omar Minai, MD; Mindi Steiger, RRT; Kenneth White, RPFT; Janet Maurer, MD (principal investigator, 1996-2001); Terri Durr, RN (2000-2001); Charles Hearn, DO (1998-2001); Susan Lubell, PA-C (1999-2000); Peter O’Donovan, MD (1998-2003); and Robert Schilz, DO (1998-2002).

Columbia University, New York, NY, in consortium with Long Island Jewish Medical Center, New Hyde Park, NY: Mark Ginsburg, MD (principal investigator); Byron Thomashow, MD (co-principal investigator); Patricia Jellen, MSN, RN (principal clinic coordinator); John Austin, MD; Matthew Bartels, MD; Yahya Berkmen, MD; Patricia Berkoski, MS, RRT (site coordinator, Long Island Jewish Medical Center); Frances Brogan, MSN, RN; Amy Chong, BS, CRT; Glenda DeMercado, BSN; Angela DiMango, MD; Sandy Do, MS, PT; Bessie Kachulis, MD; Arfa Khan, MD; Berend Mets, MD; Mitchell O'Shea, BS, RT, CPFT; Gregory Pearson, MD; Leonard Rossoff, MD; Steven Scharf, MD, $\mathrm{PhD}$ (co-principal investigator, 1998-2002); Maria Shiau, MD; Paul Simonelli, MD; Kim Stavrolakes, MS, PT; Donna Tsang, BS; Denise Vilotijevic, MS, PT; Chun Yip, MD; Mike Mantinaos, MD 
(1998-2001); Kerri McKeon, BS, RRT, RN (1998-1999); and Jacqueline Pfeffer, MPH, PT (1997-2002).

Duke University Medical Center, Durham, NC: Neil MacIntyre, MD (principal investigator); R. Duane Davis, MD (co-principal investigator); John Howe, RN (principal clinic coordinator); R. Edward Coleman, MD; Rebecca Crouch, RPT; Dora Greene; Katherine Grichnik, MD; David Harpole, Jr, MD; Abby Krichman, RRT; Brian Lawlor, RRT; Holman McAdams, MD; John Plankeel, MD; Susan Rinaldo-Gallo, MED; Sheila Shearer, RRT; Jeanne Smith, ACSW; Mark Stafford-Smith, MD; Victor Tapson, MD; Mark Steele, MD (1998-1999); and Jennifer Norten, MD (19981999).

Mayo Foundation, Rochester, Minn: James Utz, MD (principal investigator); Claude Deschamps, MD (co-principal investigator); Kathy Mieras, CCRP (principal clinic coordinator); Martin Abel, MD; Mark Allen, MD; Deb Andrist, RN; Gregory Aughenbaugh, MD; Sharon Bendel, RN; Eric Edell, MD; Marlene Edgar; Bonnie Edwards; Beth Elliot, MD; James Garrett, RRT; Delmar Gillespie, MD; Judd Gurney, MD; Boleyn Hammel; Karen Hanson, RRT; Lori Hanson, RRT; Gordon Harms, MD; June Hart; Thomas Hartman, MD; Robert Hyatt, MD; Eric Jensen, MD; Nicole Jenson, RRT; Sanjay Kalra, MD; Philip Karsell, MD; Jennifer Lamb; David Midthun, MD; Carl Mottram, RRT; Stephen Swensen, MD; Anne-Marie Sykes, MD; Karen Taylor; Norman Torres, MD; Rolf Hubmayr, MD (1998-2000); Daniel Miller, MD (1999-2002); Sara Bartling, RN (1998-2000); and Kris Bradt (1998-2002).

National Jewish Medical and Research Center, Denver, Colo: Barry Make, MD (principal investigator); Marvin Pomerantz, MD (co-principal investigator); Mary Gilmartin, RN, RRT (principal clinic coordinator); Joyce Canterbury; Martin Carlos; Phyllis Dibbern, PT; Enrique Fernandez, MD; Lisa Geyman, MSPT; Connie Hudson; David Lynch, MD; John Newell, MD; Robert Quaife, MD; Jennifer Propst, RN; Cynthia Raymond, MS; Jane Whalen-Price, PT; Kathy Winner, OTR; Martin Zamora, MD; and Reuben Cherniack, MD (principal investigator, 1997-2000).

Ohio State University, Columbus, Ohio: Philip Diaz, MD (principal investigator); Patrick Ross, MD (co-principal investigator); Tina Bees (principal clinic coordinator); Jan Drake; Charles Emery, PhD; Mark Gerhardt, MD, PhD; Mark King, MD; David Rittinger; and Mahasti Rittinger.

St Louis University, St Louis, Mo: Keith Naunheim, MD (principal investigator); Robert Gerber, MD (co-principal investigator); Joan Osterloh, RN, MSN (principal clinic coordinator); Susan Borosh; Willard Chamberlain, DO; Sally Frese; Alan Hibbit; Mary Ellen Kleinhenz, MD; Gregg Ruppel; Cary Stolar, MD; Janice Willey; Francisco Alvarez, MD (co-principal investigator, 1999-2002); and Cesar Keller, MD (co-principal investigator, 1996-2000).

Temple University, Philadelphia, Pa: Gerard Criner, MD (principal investigator); Satoshi Furukawa, MD (co-principal investigator); Anne Marie Kuzma, RN, MSN (principal clinic coordinator); Roger Barnette, MD; Neil Brister, MD; Kevin Carney, RN, CCTC; Wissam Chatila, MD; Francis Cordova, MD; Gilbert D’Alonzo, DO; Michael Keresztury, MD; Karen Kirsch; Chul Kwak, MD; Kathy Lautensack, RN, BSN; Madelina Lorenzon, CPFT; Ubaldo Martin, MD; Peter Rising, MS; Scott Schartel, MD;
John Travaline, MD; Gwendolyn Vance, RN, CCTC; Phillip Boiselle, MD (1997-2000); and Gerald O'Brien, MD (1997-2000).

University of California, San Diego, San Diego, Calif: Andrew Ries, MD, MPH (principal investigator); Robert Kaplan, PhD (co-principal investigator); Catherine Ramirez, BS, RCP (principal clinic coordinator); David Frankville, MD; Paul Friedman, MD; James Harrell, MD; Jeffery Johnson; David Kapelanski, MD; David Kupferberg, MD, MPH; Catherine Larsen, MPH; Trina Limberg, RRT; Michael Magliocca, RN, CNP; Frank J. Papatheofanis, MD, PhD; Dawn Sassi-Dambron, RN; and Melissa Weeks.

University of Maryland at Baltimore, Baltimore, Md, in consortium with Johns Hopkins Hospital, Baltimore, Md: Mark Krasna, MD (principal investigator); Henry Fessler, MD (co-principal investigator); Iris Moskowitz (principal clinic coordinator); Timothy Gilbert, MD; Jonathan Orens, MD; Steven Scharf, MD, PhD; David Shade; Stanley Siegelman, MD; Kenneth Silver, MD; Clarence Weir; and Charles White, MD.

University of Michigan, Ann Arbor, Mich: Fernando Martinez, MD (principal investigator); Mark Iannettoni, MD (coprincipal investigator); Catherine Meldrum, BSN, RN, CCRN (principal clinic coordinator); William Bria, MD; Kelly Campbell; Paul Christensen, MD; Kevin Flaherty, MD; Steven Gay, MD; Paramjit Gill, RN; Paul Kazanjian, MD; Ella Kazerooni, MD; Vivian Knieper; Tammy Ojo, MD; Lewis Poole; Leslie Quint, MD; Paul Rysso; Thomas Sisson, MD; Mercedes True; Brian Woodcock, MD; and Lori Zaremba, RN.

University of Pennsylvania, Philadelphia, Pa: Larry Kaiser, MD (principal investigator); John Hansen-Flaschen, MD (co-principal investigator); Mary Louise Dempsey, BSN, RN (principal clinic coordinator); Abass Alavi, MD; Theresa Alcorn; Selim Arcasoy, MD; Judith Aronchick, MD; Stanley Aukberg, MD; Bryan Benedict, RRT; Susan Craemer, BS, RRT, CPFT; Ron Daniele, MD; Jeffrey Edelman, MD; Warren Gefter, MD; Laura Kotler-Klein, MSS; Robert Kotloff, MD; David Lipson, MD; Wallace Miller, Jr, MD; Richard O'Connell, RPFT; Staci Opelman, MSW; Harold Palevsky, MD; William Russell, RPFT; Heather Sheaffer, MSW; Rodney Simcox, BSRT, RRT; Susanne Snedeker, RRT, CPFT; Jennifer Stone-Wynne, MSW; Gregory Tino, MD; Peter Wahl; James Walter, RPFT; Patricia Ward; David Zisman, MD; James Mendez, MSN, CRNP (1997-2001); and Angela Wurster, MSN, CRNP (1997-1999).

University of Pittsburgh, Pittsburgh, Pa: Frank Sciurba, MD (principal investigator); James Luketich, MD (co-principal investigator); Colleen Witt, MS (principal clinic coordinator); Gerald Ayres; Michael Donahoe, MD; Carl Fuhrman, MD; Robert Hoffman, MD; Joan Lacomis, MD; Joan Sexton; William Slivka; Diane Strollo, MD; Erin Sullivan, MD; Tomeka Simon; Catherine Wrona, RN, BSN; Gerene Bauldoff, RN, MSN (1997-2000); Manuel Brown, MD (1997-2002); Elisabeth George, RN, MSN (principal clinic coordinator, 1997-2001); Robert Keenan, MD (co-principal investigator, 1997-2000); Theodore Kopp, MS (1997-1999); and Laurie Silfies (1997-2001).

University of Washington, Seattle, Wash: Joshua Benditt, MD (principal investigator), Douglas Wood, MD (co-principal investigator); Margaret Snyder, MN (principal clinic coordinator); Kymberley Anable; Nancy Battaglia; Louie Boitano; Andrew Bowdle, MD; Leighton Chan, MD; Cindy Chwalik; Bruce Culver, MD; Thurman Gillespy, MD; David Godwin, MD; Jeanne Hoff- 
man; Andra Ibrahim, MD; Diane Lockhart; Stephen Marglin, MD; Kenneth Martay, MD; Patricia McDowell; Donald Oxorn, MD; Liz Roessler; Michelle Toshima; and Susan Golden (1998-2000).

\section{Other Participants}

Agency for Healthcare Research and Quality, Rockville, Md: Lynn Bosco, MD, MPH; Yen-Pin Chiang, PhD; Carolyn Clancy, MD; and Harry Handelsman, DO.

Centers for Medicare and Medicaid Services, Baltimore, Md: Steven Sheingold, PhD; Tanisha Carino, PhD; Joe Chin, MD; JoAnna Farrell; Karen McVearry; Anthony Norris; Sarah Shirey; and Claudette Sikora.

Coordinating Center, The Johns Hopkins University, Baltimore, Md: Steven Piantadosi, MD, PhD (principal investigator); James Tonascia, PhD (co-principal investigator); Patricia Belt; Karen Collins; Betty Collison; John Dodge; Michele Donithan, MHS; Vera Edmonds; Gregory L. Foster, MA; Julie Fuller; Judith Harle; Rosetta Jackson; Heather Koppelman; Shing Lee, ScM; Charlene Levine; Hope Livingston; Jill Meinert; Jennifer Meyers; Deborah Nowakowski; Kapreena Owens; Shangqian Qi, MD; Michael Smith; Brett Simon, MD; Paul Smith; Alice Sternberg, ScM; Mark Van Natta, MHS; Laura Wilson, ScM; and Robert Wise, MD.

Cost-Effectiveness Subcommittee: Robert M. Kaplan, $\mathrm{PhD}$ (chair); J. Sanford Schwartz, MD (co-chair); Yen-Pin Chiang, $\mathrm{PhD}$; Marianne C. Fahs, PhD; A. Mark Fendrick, MD; Alan J.
Moskowitz, MD; Dev Pathak, PhD; Scott Ramsey, MD, PhD; Steven Sheingold, PhD; A. Laurie Shroyer, PhD; Judith Wagner, $\mathrm{PhD}$; and Roger Yusen, MD.

Cost-Effectiveness Data Center, Fred Hutchinson Cancer Research Center, Seattle, Wash: Scott Ramsey, MD, PhD (principal investigator); Ruth Etzioni, PhD; Sean Sullivan, PhD; Douglas Wood, MD; Thomas Schroeder, MA; Karma Kreizenbeck; Kristin Berry, MS; and Nadia Howlader, MS.

CT Scan Image Storage and Analysis Center, University of Iowa, Iowa City, Iowa: Eric Hoffman, $\mathrm{PhD}$ (principal investigator); Janice Cook-Granroth, BS; Angela Delsing, RT; Junfeng Guo, PhD; Geoffrey McLennan, MD; Brian Mullan, MD; Chris Piker, BS; Joseph Reinhardt, PhD; Jered Sieren, RTR; and William Stanford, MD.

Data and Safety Monitoring Board: John A. Waldhausen, MD (chair); Gordon Bernard, MD; David DeMets, PhD; Mark Ferguson, MD; Eddie Hoover, MD; Robert Levine, MD; Donald Mahler, MD; A. John McSweeny, PhD; Jeanine Wiener-Kronish, MD; O. Dale Williams, PhD; and Magdy Younes, MD.

Marketing Center, Temple University, Philadelphia, Pa: Gerard Criner, MD (principal investigator); and Charles Soltoff, MBA.

Project Office, National Heart, Lung, and Blood Institute, Bethesda, Md: Gail Weinmann, MD (project officer); Joanne Deshler (contracting officer); Dean Follmann, PhD; James Kiley, $\mathrm{PhD}$; and Margaret $\mathrm{Wu}, \mathrm{PhD}$ (1996-2001). 